\title{
A prehospital treat-and-release protocol for supraventricular tachycardia
}

Rajan Minhas, BMLSc ${ }^{*}{ }^{\dagger}$; Gregory Vogelaar, $\mathrm{BSc}^{\dagger}$; Dongmei Wang, $\mathrm{MSc}^{\ddagger}$; Wadhah Almansoori, $\mathrm{MSc}^{\dagger}$; Eddy Lang, $\mathrm{MDCM}^{\ddagger \S}$; lan E. Blanchard, $\mathrm{MSc}^{\dagger \uparrow}$; Gerald Lazarenko, BScPh, $\mathrm{MD}^{\dagger}$; Andrew McRae, MD, $\mathrm{PhD}^{\ddagger \S}$

\section{ABSTRACT}

Objective: Paroxysmal supraventricular tachycardia (SVT) is a common dysrhythmia treated in the prehospital setting. Emergency medical service (EMS) agencies typically require patients treated for SVT to be transported to the hospital. This retrospective cohort study evaluated the impact, paramedic adherence, and patient re-presentation rates of a treat-andrelease $(T+R)$ protocol for uncomplicated SVT.

Methods: Data were linked from the Alberta Health Services EMS electronic patient care record (EPCR) database for the City of Calgary to the Regional Emergency Department Information System (REDIS). All SVT patients treated by EMS between September 1, 2010, and September 30, 2012, were identified. Databases were queried to identify re-presentations to EMS or an emergency department (ED) within 72 hours of $T+R$.

Results: There were 229 confirmed SVT patient encounters, including $75 \mathrm{~T}+\mathrm{R}$ events. Of these $75 \mathrm{~T}+\mathrm{R}$ events, 10 (13\%, $95 \%$ confidence interval $[\mathrm{Cl}][7.4,23])$ led to an EMS representation within 72 hours, and $4(5 \%, 95 \% \mathrm{Cl}[2.1,13])$ led to an ED. All re-presentations were attributed to a single individual. After excluding 15 records that were incomplete due to limitations in the EPCR platform, 43 of $60(72 \%) T+R$ encounters met all protocol criteria for $T+R$.

Conclusion: The $T+R$ protocol evaluated in this study applied to a significant proportion of patients presenting to EMS with SVT. Risk of re-presentation following $T+R$ was low, and paramedic protocol adherence was reasonable. $T+R$ appears to be a viable option for uncomplicated SVT in the prehospital setting.

\section{RÉSUMÉ}

Objectif: La tachycardie supraventriculaire paroxystique (TSV) est un trouble du rythme fréquent, traité en milieu préhospitalier. Les organismes de services médicaux d'urgence (SMU) demandent généralement que les patients traités pour de la TSV soient transportés à I'hôpital. II sera question ici d'une étude de cohortes, rétrospective, qui visait à évaluer la portée d'un protocole de traitement préhospitalier seul (TPHS), sur place, de TSV simple; le respect de ce protocole par les ambulanciers paramédicaux et le taux de deuxième consultation par les patients ainsi traités. Méthode: Un lien a été établi entre la base de données de I'Alberta Health Services EMS Electronic Patient Care Record (EPCR), située à Calgary, et le système Regional Emergency Department Information System (REDIS). Ont ainsi été dégagés tous les cas de TSV traités par les SMU, entre le $1^{\text {er }}$ septembre 2010 et le 30 septembre 2012. La recherche dans les bases de données visait à relever les deuxièmes appels aux SMU ou les nouvelles consultations dans des services d'urgence (SU) dans les 72 heures suivant l'application du protocole TPHS.

Résultats: II y a eu 229 cas confirmés de TSV, dont 75 traités selon le protocole TPHS. Sur ces derniers, 10 (13\%, $\mathrm{Cl}$ à $95 \%$ : 7,4-23) se sont soldés par un deuxième appel aux SMU dans les 72 heures et 4 (5\%; $\mathrm{Cl}$ à $95 \%$ : 2,1-13]), par une consultation dans des $\mathrm{SU}$. Toutes ces nouvelles consultations ne concernaient qu'une seule personne. Après le rejet de 15 dossiers incomplets en raison de restrictions de la plateforme EPCR, 43 consultations sur 60 (72\%) répondaient à tous les critères du protocole TPHS.

Conclusions: Le protocole TPHS évalué dans l'étude décrite ici a été appliqué à une proportion importante de patients ayant appelé les SMU pour de la TSV. Le risque de nouvelle consultation après le protocole TPHS était faible, et les ambulanciers paramédicaux ont fait preuve d'une application judicieuse du protocole. Bref, le protocole TPHS semble une solution viable pour les cas simples de TSV en milieu préhospitalier.

Keywords: emergency medical services, supraventricular tachycardia, treat and release, non-transport, paramedic, adult, advanced cardiac life support

\section{INTRODUCTION}

Emergency department (ED) crowding and increased demand for access to emergency medical services

From the *Faculty of Medicine, University of Calgary, AB; †Alberta Health Services, Emergency Medical Services, Calgary, AB; $¥ A l b e r t a$ Health Services, Department of Emergency Medicine, Calgary, AB; §Department of Emergency Medicine, University of Calgary, AB; and $\uparrow$ Department of Community Health Sciences, Faculty of Medicine, University of Calgary, AB.

Correspondence to: Dr. Andrew McRae, Emergency Department, Foothills Medical Centre, Rm C231 140329 St NW, Calgary, AB T2N 2T9; Andrew.McRae@albertahealthservices.ca 
(EMS) is a growing reality across most of Canada and the United States. ${ }^{1,2}$ In order to minimize the burden on EDs and increase availability of EMS resources, many EMS agencies have implemented treatment pathways other than the standard response and transport to ED model. One particular strategy is that of treat and release $(T+R)$. The principle behind $T+R$ protocols is that a subset of patients can be identified and treated safely in the field, without subsequent evaluation by a physician in an ED. The potential benefits to such protocols include reduced operational burden on EDs, reduced health care costs, and increased patient satisfaction.

Paroxysmal supraventricular tachycardia (SVT) is a common cardiac dysrhythmia that rarely results in serious adverse events. ${ }^{3}$ Most EMS agencies providing advanced life support have protocols for the prehospital treatment of SVT. These typically follow guidelines established by the International Liaison Committee on Resuscitation as a standard of care. These treatments include vagal manoeuvres, intravenous adenosine, and electrical cardioversion. ${ }^{4}$ Previous studies have established the value and safety of treating these patients out of the hospital, ${ }^{5-9}$ but the evidence base for an SVT $\mathrm{T}+\mathrm{R}$ protocol is sparse.

A number of EMS $\mathrm{T}+\mathrm{R}$ protocols have previously been described in the literature as safe and effective in reducing the transport of select patients. ${ }^{10-14}$ The medical conditions for which $\mathrm{T}+\mathrm{R}$ protocols have been previously described are acute hypoglycemia ${ }^{12-14}$ and opioid overdoses. ${ }^{10,11}$ The widespread implementation of $\mathrm{T}+\mathrm{R}$ protocols for other conditions has not yet occurred. This may be due to safety concerns surrounding non-transport of patients and a lack of empirical evidence assessing their effectiveness, efficiency, and safety. Non-transported patients consistently remain the greatest source of litigation for EMS agencies. ${ }^{15,16} \mathrm{~T}+\mathrm{R}$ protocols aim to minimize the risk of adverse events by using explicit selection criteria designed to identify low-risk patients.

The purpose of this retrospective cohort study is to evaluate the impact, paramedic adherence, and patient re-presentation rates of a $T+R$ protocol enabling advanced life support paramedics to treat SVT in the field, without subsequent transport to an ED.

\section{METHODS}

This is a retrospective cohort study using linked data from the Alberta Health Services (AHS) EMS electronic patient care record (EPCR) database for the City of Calgary to the AHS Calgary Zone Regional Emergency Department Information System (REDIS) database. All SVT patients in the EPCR database treated between September 1, 2010, and September 30, 2012, were identified and linked to the REDIS database. Although the protocol was initially implemented in the City of Calgary in 1998, the time period was selected for study as the first 2 calendar years subsequent to implementation of standardized provincial EMS protocols. This study was approved by the University of Calgary Conjoint Health Research Ethics Board.

\section{Patient population and identification}

Patients were identified by electronic query of the AHS EMS EPCR database, and linkage to the Calgary Zone REDIS database. All adult patients ages 18-65 identified as having been treated by Calgary Zone EMS for SVT during the study period were included. Linkage was done primarily using personal health numbers (PHNs) or, in cases where PHNs were not available, name and date-of-birth identifiers, in combination with the date of index presentation. The EPCR and REDIS databases were queried to determine whether patients re-presented within 72 hours of the initial event, either to EMS or a regional ED in the Calgary Metro Region. This follow-up period was chosen because 72 hours is likely sufficient to include all major adverse events that might be related to an index SVT episode.

Presumed SVT patients were identified within the EPCR database using the following search strategy: "Calgary Metro Region AND 18-65 years old AND September 1, 2010 - September 30, 2012 AND finalized PCR AND (received adenosine OR received vagal maneuver OR ECG interpretation of supraventricular tachycardia OR working diagnoses free text search [nct, SVT, psvt, supra-vent, supra vent, supravent])."

Patients identified by the EPCR database search strategy were initially classified by a registered paramedic (GV) as being $\mathrm{T}+\mathrm{R}$ or treat and transport using the disposition field of EPCRs. All events were then evaluated by a registered paramedic (RM) using the chief complaint, vitals, treatments, electrocardiogram (ECG), and comments sections of EPCR forms in order to determine whether events were correctly identified by the treating paramedic as SVT. Non-SVT encounters were eliminated from results. For results in which it 
was unclear whether encounters were correctly identified as SVT, based upon initial screening, a second independent chart review occurred by an emergency physician (AM). Discrepancies were resolved by consensus.

EPCR encounters were determined to be SVT by the following criteria: paramedic documentation of the rhythm as SVT and a history of or witnessed abrupt onset of heart rate $>100$ beats per minute, successful conversion of SVT using vagal maneuvers or adenosine, or 12-lead ECG demonstrating SVT as determined by reviewers (if ECG was available).

\section{Study setting}

AHS, the provincial health agency of the province of Alberta, is responsible for providing EMS services in Alberta. This study specifically examined patients that were assessed and treated in the Calgary metropolitan zone (i.e., the City of Calgary), representing a population of 1.1 million inhabitants. At the time that this study was performed, the AHS Calgary zone included three adult academic EDs seeing a combined census of approximately 230,000 patients annually. The REDIS database includes patient identifiers, demographics, ED presenting complaint and discharge diagnoses, laboratory results, and electronic time stamps for all patient care encounters at all ED sites.

AHS EMS responds to approximately 118,000 calls for service annually in the Calgary zone, with 77,000 classified as emergency calls, 28,000 non-emergency calls, 7,000 transfers, and 6,000 "other" calls. The service is run as all advanced life support system, in which essentially all ambulances have at least one advanced life support provider, a registered emergency medical technologist-paramedic (EMT-P). EMS care in Alberta is documented on an EPCR platform in which practitioners complete patient care records on mobile tablet computers. The EPCR database is searchable to identify events in which particular interventions or protocols were performed, and facilitates the aggregation of study data.

\section{Practitioner training}

EMT-Ps received dedicated training in the City of Calgary $T+R$ protocol at the time of implementation, in March of 1998, prior to the study period. At the time of provincial takeover of EMS delivery in Alberta
(2009), training in the current provincial $\mathrm{T}+\mathrm{R}$ protocol was included as a part of implementation of provincial medical control protocols.

\section{AHS EMS protocol for treatment of SVT}

The current AHS treatment protocol for out-ofhospital patients with presumed SVT is shown in Figure $1 .{ }^{17}$ The protocol adheres closely to American Heart Association Advanced Cardiac Life Support guidelines for the management of SVT, but deviates in the initial dose of adenosine. This change occurred part way through the study period (December 2010), when the initial adenosine dose was changed from 6 to $12 \mathrm{mg}$. This change was implemented as a part of EMS protocol updates implemented by local expert consensus.

Patients who require more than a single dose of adenosine, or synchronized cardioversion, are excluded from eligibility to $T+R$. All other patients who are successfully converted to sinus rhythm are screened by treating paramedics for eligibility to $T+R$.

\section{AHS treat-and-release criteria for SVT}

The AHS T+R criteria for SVT are shown in Table $1 .{ }^{17}$ Because there were no previously reported $\mathrm{T}+\mathrm{R}$ protocols for SVT, the criteria were established by local expert consensus. These criteria are documented within the EPCR platform as a check box template with drop-down selections that indicate whether each criterion is met. As a condition of any patient being treated and released, an information sheet is provided to patients. This sheet is not specific to the $\mathrm{T}+\mathrm{R}$ protocol, but rather provides options for followup, including a repeat call to 9-1-1, a 24-hour provincial nurse-staffed telephone hotline, and/or the option to follow up with a family physician or in an ED.

\section{Data analysis}

The primary outcome assessed was re-presentation to EMS or an ED. Secondary outcomes included cardiac arrest, defibrillation, and synchronized cardioversion. Paramedic adherence to $\mathrm{T}+\mathrm{R}$ criteria, as well as effectiveness of vagal manoeuvres and adenosine were also quantified.

The evaluation of a 2-year time period was based upon previous AHS EMS quality assurance analysis estimating 100 SVT patients treated and released by 


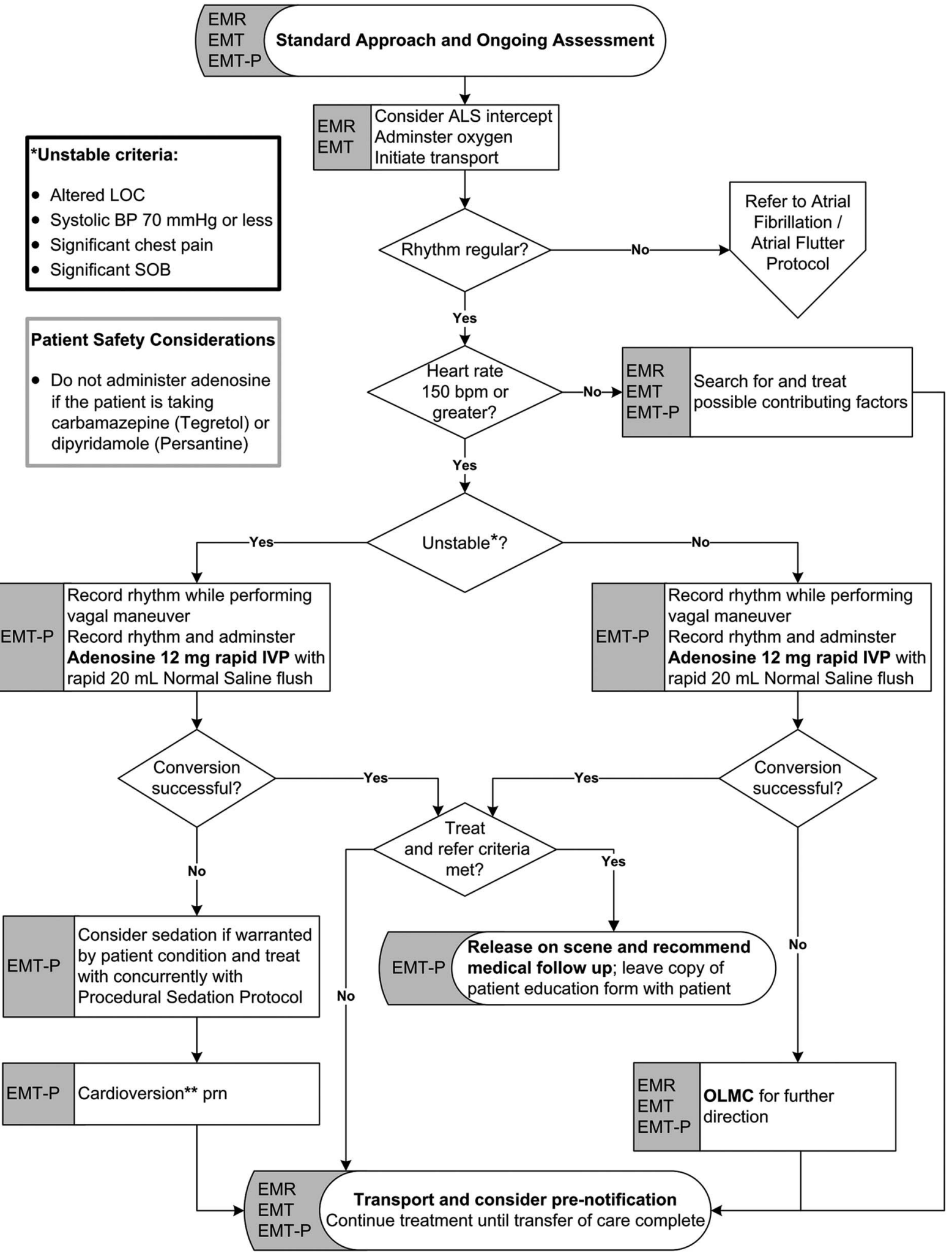

Figure 1. AHS protocol for the treatment of SVT patients.

$\mathrm{LOC}=$ level of consciousness; $\mathrm{BP}=$ blood pressure; $\mathrm{SOB}=$ shortness of breath; $\mathrm{ALS}=$ advanced life support; IVP = intravenous push; OLMC = online medical consultation; PRN = as required. 
Table 1. AHS emergency medical services treat-and-release criteria for supraventricular tachycardia

- The patient is between 18 and 65 years of age.

- The patient has a history of recurrent SVT known to be responsive to adenosine or vagal manoeuvres, without previous recurrence of SVT shortly following treatment.

- The patient does not have any concurrent acute illness.

- The patient has remained asymptomatic and hemodynamically stable for at least 15 minutes post-conversion.

- The patient has not experienced an episode of SVT requiring treatment in the past 24 hours.

- The patient agrees and is comfortable with the decision not to be transported to the hospital at this time.

- The patient has the means to immediately call 9-1-1 if symptoms recur, and EMS advises the patient to do this.

- There is a responsible adult who will remain with the patient for at least 4 hours.

- EMS has answered all patient questions about their care.

- The patient has signed the release waiver on the SVT information sheet.

- The patient understands and agrees to follow EMS recommendations for follow-up care.

- The SVT treat-and-refer patient information sheet was left with someone at the scene.

EMS = emergency medical services; SVT = supraventricular tachycardia.

EMS in Calgary per year. Counts and descriptive statistics were used, with $95 \%$ confidence intervals (CIs) for point estimates. Based on an estimate of 100 encounters per year (total $n=200$ ), this sample size would allow a $95 \%$ CI of $2.74-8.96$ around a $\mathrm{T}+\mathrm{R}$ representation incidence point estimate of $5.0 \%$.

\section{RESULTS}

The EPCR search strategy returned 286 possible SVT patient encounters during the study period. Of these patient encounters, 204 were confirmed as SVT events, 45 were excluded as non-SVT, and 37 were indeterminate. Of these 37 events, chart reviews confirmed 25 encounters as SVT and 12 as non-SVT. Of the total 229 confirmed SVT events, 130 patients were treated and transported, 72 were treated and released, 1 was a patient refusal of transport, and 26 had an unclear disposition. These 26 encounters were unclear due to an uncompleted EPCR response outcome field and were resolved by manual chart review as 23 treat and transport and three $\mathrm{T}+\mathrm{R}$ encounters. Figure 2 summarizes the results as 229 total SVT patient encounters, $153(67 \%)$ of which were transported to the hospital, $1(0.4 \%)$ that was excluded due to patient refusal of transport against medical advice, and 75 (33\%) of which were $T+R$.

EPCR chart reviews were completed for all $75 \mathrm{~T}+\mathrm{R}$ encounters and identified 40 unique individuals. The mean age of patient encounters was 53, and 43 encounters involved male patients. The mean heart rate of patients presenting in SVT was 174 (standard deviation $=26$ ).

Queries of the EPCR and REDIS databases identified 10 re-presentations to EMS within 72 hours of being treated and released (13\%, 95\% CI [7.4, 23]), and 4 direct patient presentations to an $\mathrm{ED}(5 \%, 95 \% \mathrm{CI}$ [2.1, 13]). All 14 re-presentations could be attributed to a single individual, a 62-year-old male with multiple medical co-morbidities, and none resulted in cardiac arrest, defibrillation, or synchronized cardioversion. Four of the individuals' EMS re-presentations resulted in a second $\mathrm{T}+\mathrm{R}$ event for SVT (these $4 \mathrm{~T}+\mathrm{R}$ events are included in the total population of $75 \mathrm{~T}+\mathrm{R}$ encounters). Of the remaining six EMS re-presentations, four resulted in treat and transport to hospital, and two resulted in non-protocol non-transport to the hospital (i.e., the patient refused or met criteria for an unrelated $\mathrm{T}+\mathrm{R}$ protocol). Of the four $\mathrm{ED}$ representations following a $T+R$ event, two resulted in treatment and discharge for SVT, whereas two resulted in admission for unrelated conditions. The admission diagnoses for these two events were an exacerbation of chronic obstructive pulmonary disease and a gastrointestinal bleed. Of interest is that in both of these unrelated admissions, a note was made of being in SVT at the time of ED presentation, or immediately before.

When assessing adherence to $T+R$ protocol criteria, there were a total of 43 of 75 encounters $(57 \%, 95 \%$ CI [46, 68]), for which all criteria were met and 


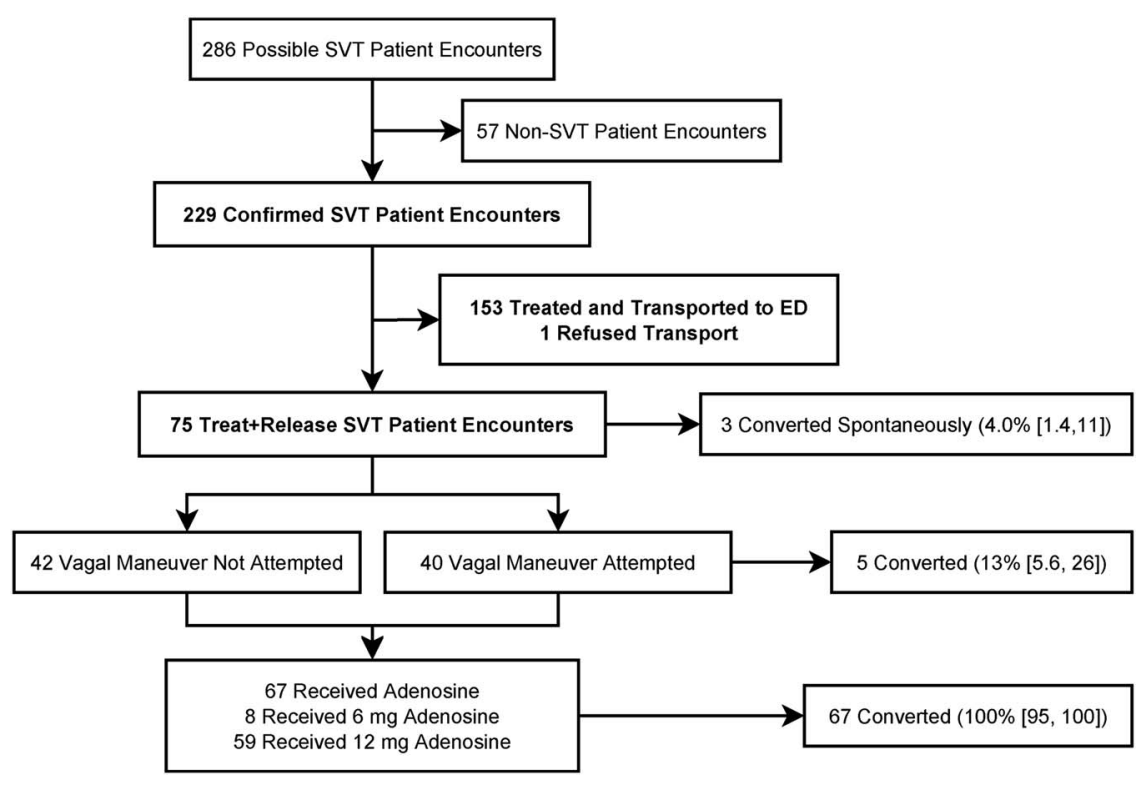

Figure 2. Flow chart of patient encounters by disposition and treatment(s) received. SVT = supraventricular tachycardia; ED = emergency department.

documented. Due to a limitation of the EPCR platform, some criteria were not documented on early study patient care record (PCR) forms. At the start of the investigational period, there was no drop-down box allowing practitioners to indicate that the patient received an information sheet (5 encounters affected), that the patient understood and agreed to instructions for follow-up care (15 encounters affected), and that all patient questions had been answered (15 encounters affected). If these encounters were excluded, 43 out of $60(72 \%, 95 \%$ CI $[59,82])$ encounters were documented as having met all protocol criteria for $\mathrm{T}+\mathrm{R}$.

Twenty-two protocol violations occurred over 17 $\mathrm{T}+\mathrm{R}$ encounters. Excluding encounters for which there were limitations in the EPCR system, the most common protocol breaches were the failure to provide patients with an SVT information sheet $(n=9)$ and failing to ensure that there would be a responsible adult with the patient for 4 hours post-treatment $(n=5)$. Of the remaining criteria breaches, three did not have EMS providers wait with them for 15 minutes, two had concurrent illnesses, one did not have a previous history of SVT, one refused to sign the release form, and one had a previous SVT event within the past 24 hours requiring therapy.

Treatments administered during $\mathrm{T}+\mathrm{R}$ encounters are detailed in Figure 2. Due to a protocol change part way through the study, eight conversions were performed with $6 \mathrm{mg}$ of adenosine, and the remaining
59 with $12 \mathrm{mg}$. All patients treated with adenosine converted successfully with a single dose.

\section{DISCUSSION}

This study reports the impact, paramedic adherence, and patient re-presentation rates of a $\mathrm{T}+\mathrm{R}$ protocol to allow advanced life support paramedics to treat SVT in the field without transport to an ED.

The key concern with any $\mathrm{T}+\mathrm{R}$ protocol is to ensure the safety of patients who are not transported to hospital. By searching the EPCR/REDIS databases for representations to EMS or an ED within 72 hours of a $\mathrm{T}+\mathrm{R}$ event, the authors aimed to detect any adverse events (including sudden death) that might have occurred. In this study, not only were no deaths detected, but also there were no life-threatening representations to EMS or an ED following application of the $T+R$ protocol. The negligible adverse event risk found by this study is likely due, in part, to the inherently low adverse event incidence of SVT. ${ }^{3}$ This characteristic of SVT is what makes it an ideal candidate for consideration of a $\mathrm{T}+\mathrm{R}$ protocol.

In addition, this study found a low re-presentation rate to EMS or an ED. Only 14 of 75 (19\%) T+R encounters generated a re-presentation within 72 hours, and all could be attributed to a single individual. Even in these 14 re-presentations, no adverse events were documented, and 4 encounters resulted in a second 
$T+R$ event. Previous studies looking at $T+R$ of the acute hypoglycemic patient have found re-presentation rates between $6 \%-30 \% .^{12-14,18-20}$

This study suggests that EMS practitioners are able to follow a $\mathrm{T}+\mathrm{R}$ protocol criteria with reasonable adherence $(72 \%$, if taking into consideration technical difficulties with the EPCR system). The protocol is cautious but was designed to maximize specificity for low-risk patients. Only 4 of 22 protocol violations related to patient selection (concurrent illness, history of SVT, and a prior event within 24 hours), whereas the remaining 16 related to logistical non-patient factors.

The degree of paramedic compliance found by this study, given the number of $\mathrm{T}+\mathrm{R}$ criteria, may be explained by an integral checkbox form completed on each EPCR for $\mathrm{T}+\mathrm{R}$ events. This form explicitly outlines all $\mathrm{T}+\mathrm{R}$ eligibility criteria, detailed in Table 1 , and ensures that the paramedic verifies each criterion before finalizing an EPCR record. If a checkbox is not completed, a warning flag reminds practitioners that the criteria must be met for $\mathrm{T}+\mathrm{R}$ to occur (although this can be manually overridden).

Paramedic adherence to protocol could likely be improved in this system by ensuring that there are adequate patient information sheets available and stocked on every ambulance. Changes to logistical $\mathrm{T}+\mathrm{R}$ criteria could be considered once the safety of the protocol is verified.

While the majority of patients treated for SVT by EMS in this study were transported to hospital, an important proportion of patients were treated and released. Because there were 10 patient encounters that resulted in a re-presentation to EMS and 4 to an ED, a total of $61 \mathrm{ED}$ visits were potentially avoided using this protocol over a 25 -month window.

We compared our findings to an internal audit conducted shortly after the $T+R$ protocol was initiated in 1998 and published as an abstract in $2001 .^{21}$ That audit was limited to paper charts, and only 18 of 81 (23\%) patients were treated and released, in spite of a $92 \%$ conversion rate in the field. ${ }^{21}$ There were no adverse events reported in that sample, and there were no re-presentations within 72 hours of being treated and released.

\section{LIMITATIONS}

One limitation of this study was the potential misclassification of non-SVT rhythms as SVT. Due to poor availability of ECGs for the confirmation of rhythm, the determination of whether an event was
SVT was based upon the treating paramedic's determination, a documented response to vagal manoeuvres or adenosine, and a history of abrupt onset of a tachycardia $>100 \mathrm{bpm}$. The effect of this error, if any, is likely small, because the balance of evidence from each event was considered to determine whether the event was likely to be SVT. The determination of paramedic accuracy of rhythm analysis was not evaluated as an objective of this study and may warrant evaluation before widespread implementation.

In addition, because documentation of adherence was used as a proxy for actual adherence, it is likely that there were some instances in which paramedics complied with protocol requirements but did not document the compliance adequately. This would have resulted in an underestimation of protocol adherence.

In limiting follow-up searches to EMS and ED databases, there was the potential that some patients were missed on the follow-up. For example, if there were a sudden death that occurred but was not discovered within 72 hours of the initial $T+R$ event, or occurred in a patient with expected death, this would not have been captured by our search strategy. In addition, if a patient were to seek follow-up care with EMS or an ED outside of the Calgary zone, they too would have been missed. It was not practically feasible to pursue follow-up events in EDs outside of the Calgary zone, because there is no easily accessible database of patient records for these facilities. However, REDIS is updated regularly with outpatient mortality data from Alberta Vital Statistics, so deaths within Alberta would have been captured. Given the low adverse event incidence associated with SVT, the likelihood of missed adverse events is small. Although there were no adverse events detected in this study, the small sample size (75 total $\mathrm{T}+\mathrm{R}$ events) limits the ability to make conclusions regarding the safety of the protocol.

Due to the limited sample size, CIs around point estimates are wide. Recurrent events by a single individual inflated our estimate of the proportion of $T+R$ patients with 72-hour re-presentations.

This study did not evaluate whether any patients eligible for $\mathrm{T}+\mathrm{R}$ were transported to the hospital (i.e., underutilization of the $T+R$ protocol). It is possible that practitioners are hesitant to treat and release SVT patients without knowledge of the safety of the protocol. In addition, certain logistical criteria could have excluded patients from the $T+R$ protocol that would have been unlikely to impact patient outcome (i.e., having a patient information 
form available or ensuring that a responsible adult stays with the patient for at least 4 hours). Therefore, our study likely underestimated the proportion of SVT patients who met criteria for the $T+R$ protocol.

Finally, it was beyond the scope of this study to determine the operational impact of implementing a $\mathrm{T}+\mathrm{R}$ protocol. This would require evaluation of $\mathrm{a}$ number of factors, including a comparison of scene times for $\mathrm{T}+\mathrm{R}$ patients as compared to transport to the hospital. In addition, any costs in implementing a $\mathrm{T}+\mathrm{R}$ protocol, including patient education materials or practitioner training, would have to be considered. For EMS agencies that already treat SVT in the field, however, the addition of a $T+R$ protocol would not likely require a significant expenditure of resources or time. It would also be important to determine the preferences of patients regarding $\mathrm{T}+\mathrm{R}$ or transport to the hospital.

\section{CONCLUSION}

The $\mathrm{T}+\mathrm{R}$ protocol evaluated in this study applied to a significant subset of patients presenting to EMS with SVT, over a 2-year period, and was implemented with reasonable protocol adherence by paramedics. The study demonstrated a low rate of patient re-presentation after $T+R$ and suggests that $T+R$ is a viable option for uncomplicated SVT in the prehospital setting.

Competing interests: The Canadian Institutes of Health Research supported this research through its health professional student research awards.

\section{REFERENCES}

1. Committee on the Future of Emergency Care in The United States Health System, Board on Health Care Services. Institute of Medicine of the National Academies. Future of Emergency Care Series: Emergency Medical Services, At the Crossroads. Washington, D.C.; The National Academy Press: 2007.

2. Canadian Association of Emergency Physicians. Position statement on emergency department overcrowding; 2009. Available at: http://caep.ca/sites/caep.ca/files/caep/files/edoc position_statement_board_approved_june_2009_gl.pdf (accessed February 11, 2015).

3. Wood KA, Drew BJ, Scheinman MM. Frequency of disabling symptoms in supraventricular tachycardia. Am 7 Cardiol 1997 Jan 15;79(2):145-9.

4. Deakin CD, Morrison LJ, Morley PT, et al. Part 8: Advanced life support: 2010 International Consensus on Cardiopulmonary Resuscitation and Emergency Cardiovascular Care Science with Treatment Recommendations. Resuscitation 2010 Oct;81 Suppl 1:e93-174.
5. Gausche M, Persse DE, Sugarman T, et al. Adenosine for the prehospital treatment of paroxysmal supraventricular tachycardia. Ann Emerg Med 1994 Aug;24(2):183-9.

6. Furlong R, Gerhardt RT, Farber P, et al. Intravenous adenosine as first-line prehospital management of narrowcomplex tachycardias by EMS personnel without direct physician control. Am 7 Emerg Med 1995 Jul;13(4):383-8.

7. Lozano M Jr, McIntosh B, Giordano L. Effect of adenosine on the management of supraventricular tachycardia by urban paramedics. Ann Emerg Med 1995;26(6):691-6.

8. Madsen CD, Pointer JE, Lynch TG. A comparison of adenosine and verapamil for the treatment of supraventricular tachycardia in the prehospital setting. Ann Emerg Med 1995 May;25(5):649-55.

9. McCabe JL, Adhar GC, Menegazzi JJ, et al. Intravenous adenosine in the prehospital treatment of paroxysmal supraventricular tachycardia. Ann Emerg Med 1992 Apr;21(4):358-61.

10. Vilke GM, Buchanan J. Are heroin overdose deaths related to patient release after prehospital treatment with naloxone? Prehosp Emerg Care 1999;3(3):183-6.

11. Vilke GM, Sloane C, Smith AM, et al. Assessment for deaths in out-of-hospital heroin overdose patients treated with naloxone who refuse transport. Acad Emerg Med 2003 Aug; 10(8):893-6.

12. Lerner EB, Billittier AJ, Lance DR, et al. Can paramedics safely treat and discharge hypoglycemic patients in the field? Am 7 Emerg Med 2003 Mar; 21(2):115-20.

13. Socransky SJ, Pirrallo RG, Rubin JM. Out-of-hospital treatment of hypoglycemia: refusal of transport and patient outcome. Acad Emerg Med 1998 Nov; 5(11):1080-5.

14. Mechem CC, Kreshak AA, Barger J, et al. The short-term outcome of hypoglycemic diabetic patients who refuse ambulance transport after out-of-hospital therapy. Acad Emerg Med 1998 Aug; 5(8):768-72.

15. Jaslow D, Barbera JA, Johnson E, et al. EMS-initiated refusal and alternative methods of transport. Prehosp Emerg Care Informa UK Ltd UK 1998;2(1):18-22.

16. Schaefer RA, Rea TD, Plorde M, et al. An emergency medical services program of alternate destination of patient care. Prehosp Emerg Care 2002;6(3):309-14.

17. AHS EMS Provincial Medical Control Protocols. Alberta Health Services; 2010. Available at: https://www.ahsems. com/public/AHS/protocols/index.html (accessed February 10, 2015).

18. Cain E, Ackroyd-stolarz S, Alexiadis P, et al. Prehospital hypoglycemia: the safety of not transporting treated patients. Prehosp Emerg Care 2003;7(4):458-65.

19. Roberts K, Smith A. Outcome of diabetic patients treated in the prehospital arena after a hypoglycaemic episode, and an exploration of treat and release protocols: a review of the literature. Emerg Med 72003 May; 20(3):274-6.

20. Strote J, Simons R, Eisenberg M. Emergency medical technician treatment of hypoglycemia without transport. $\mathrm{Am}$ 7 Emerg Med 2008 Mar;26(3):291-5.

21. Yahn S, De Maio VJ, Gant PT, et al. Compliance and safety of a prehospital treatment-and-release protocol for narrowcomplex tachycardia patients. Prehosp Emerg Care Abstract \#18, NAEMSP 2001 Annual Meeting. Fort Myers, Florida. 2001;5(1):107. 